STONE CENTER ON SOCIO-ECONOMIC INEQUALITY

WORKING PAPER SERIES

No. 13

Poor Laborers and Rich Capitalists?

On the Evolution of Income Composition Inequality in Italy 1989-2016

Roberto lacono

Marco Ranaldi

March 2020

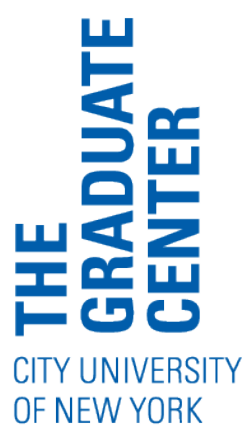




\title{
Poor laborers and rich capitalists? On the evolution of income composition inequality in Italy 1989-2016*
}

\author{
Roberto Iacono $^{\dagger} \quad$ Marco Ranaldi ${ }^{\ddagger}$
}

March 20, 2020

\begin{abstract}
We study the evolution of inequality in income composition in terms of capital and labor income in Italy between 1989 and 2016. We document a rise in the share of capital income accruing to the bottom of the distribution, whilst the top of the distribution increases its share of labor income. This implies a falling degree of income composition inequality in the period considered and, hence, the fact that Italy is moving away from being an economy composed of poor laborers and rich capitalists. This result is robust to the use of different definitions of capital and labor income. A falling degree of income composition inequality implies a weaker link between the functional and personal distributions of income. Therefore, fluctuations in the total factor shares of income are having an increasingly weaker impact on income inequality in Italy. Finally, we conceptualize a rule of thumb for policy makers seeking to reduce income inequality in the long run. This rule relates fluctuations in the total factor shares and the level of income composition inequality to the specific income source to be redistributed.
\end{abstract}

JEL-Classification: D31, D33, D63, E25.

Keywords: Income composition inequality, functional and personal distribution, Italy.

${ }^{*}$ We thank F. Bloise, A. Brandolini, E. Felice, B. Milanovic, S. Morelli, E. Palagi, F. Patriarca, M. Raitano, A. Roventini, F. Saraceno, E. Stockhammer; participants at the 8th ECINEQ Meeting of the Society for the Study of Economic Inequality held at the Paris School of Economics (PSE), participants at the 60th annual conference of the Italian Economic Association held at the University of Palermo, and anonymous reviewers for their helpful comments and suggestions. All data and codes to fully replicate the results of this paper are publicly available on OSF. The usual disclaimer applies.

†Corresponding author's address: Norwegian University of Science and Technology, Campus Tunga, Tungasletta 2, NO-7491, Trondheim, Norway. E-mail: roberto.iacono@ntnu.no.

${ }^{\ddagger}$ Stone Center on Socio-Economic Inequality, The Graduate Center, City University of New York (CUNY). E-mail: mranaldi@gc.cuny.edu. 


\section{Introduction}

To motivate our study of the evolution of income composition inequality in Italy, we introduce several stylized facts about factor incomes. Table 1 shows the concentration of capital income across the income distribution (excluding pensions and transfers) for Italy between 1989 and 2016. ${ }^{1}$ Four income groups (in terms of total income) are considered, namely, the poorest $50 \%$, the middle $40 \%$, and the richest $10 \%$, which is further divided into the bottom half $(90-95 \%)$ and the top half $(95-100 \%)$ of the decile. Note that we consider capital income to be the sum of property income and the capital component of self-employment income.

Table 1: Capital income shares by income group

\begin{tabular}{cccccccc}
\hline \hline Income group & 1989 & 1995 & 2000 & 2004 & 2008 & 2012 & 2016 \\
\hline \hline $0-50 \%$ & $5 \%$ & $10 \%$ & $10 \%$ & $10 \%$ & $9 \%$ & $15 \%$ & $16 \%$ \\
$50-90 \%$ & $39 \%$ & $37 \%$ & $37 \%$ & $35 \%$ & $39 \%$ & $35 \%$ & $36 \%$ \\
$90-95 \%$ & $16 \%$ & $15 \%$ & $14 \%$ & $14 \%$ & $15 \%$ & $13 \%$ & $13 \%$ \\
$95-100 \%$ & $40 \%$ & $38 \%$ & $38 \%$ & $41 \%$ & $36 \%$ & $36 \%$ & $34 \%$ \\
\hline \hline Capital Share & $27 \%$ & $27 \%$ & $30 \%$ & $31 \%$ & $28 \%$ & $28 \%$ & $27 \%$ \\
Gini (total income) & 0.31 & 0.40 & 0.39 & 0.42 & 0.40 & 0.40 & 0.42 \\
\hline \hline
\end{tabular}

Note: The source for both the raw data and sample weights is SHIW, Bank of Italy. Both the aggregate capital share and the Gini coefficient for total income are computed by the authors using SHIW data.

Table 1 should be read as follows: in 1989, the bottom 50\% in terms of total income earned approximately $5 \%$ of the capital income in the economy. The richest $10 \%$ of the distribution earned approximately $56 \%$ of the share of capital income in the same year.

A comparison of 1989 with the most recent year for which data are available, 2016, shows that concentration of capital income increased at the bottom of the total income distribution. In 2016, the capital income accruing to the bottom 50\% had increased by $11 \%$, with respect to 1989 , while the share accruing to the top $50 \%$ decreased correspondingly by $11 \%$. Overall, the capital share of income had increased by 4 percentage points as of 2004, before it decreased in the post-crisis years back to the level of the early 1990s.

We next examine Table 2, which reports the concentration of labor income across the income distribution (excluding pensions and transfers).

\footnotetext{
${ }^{1}$ Data source for both raw data and sample weights: Bank of Italy.
} 
Table 2: Labor income shares by income group

\begin{tabular}{cccccccc}
\hline \hline Income group & 1989 & 1995 & 2000 & 2004 & 2008 & 2012 & 2016 \\
\hline \hline $0-50 \%$ & $38 \%$ & $28 \%$ & $29 \%$ & $29 \%$ & $30 \%$ & $25 \%$ & $26 \%$ \\
$50-90 \%$ & $46 \%$ & $52 \%$ & $52 \%$ & $52 \%$ & $51 \%$ & $54 \%$ & $54 \%$ \\
$90-95 \%$ & $7 \%$ & $8 \%$ & $8 \%$ & $8 \%$ & $8 \%$ & $9 \%$ & $8 \%$ \\
$95-100 \%$ & $8 \%$ & $11 \%$ & $10 \%$ & $10 \%$ & $11 \%$ & $11 \%$ & $12 \%$ \\
\hline \hline Labor Share & $73 \%$ & $73 \%$ & $70 \%$ & $69 \%$ & $72 \%$ & $72 \%$ & $73 \%$ \\
Gini (total income) & 0.31 & 0.40 & 0.39 & 0.42 & 0.40 & 0.40 & 0.42 \\
\hline \hline
\end{tabular}

Note: The source for both the raw data and sample weights is SHIW, Bank of Italy. Both the aggregate labor share and the Gini coefficient for total income are computed by the authors using SHIW data.

Table 2 shows that the bottom 50\% went from earning $38 \%$ of labor income in 1989 to approximately $26 \%$ in 2016, while the richest $50 \%$ increased its fraction of labor income from $61 \%$ to $74 \%$ over the period considered. In other words, we observe the opposite pattern for labor income as that observed for capital income: a significant fraction of labor income shifted from the bottom $50 \%$ to the top $50 \%$ of the income distribution from 1989 to 2016 . Overall, the labor share of income initially lost $4 \%$ to the capital share throughout the 1990 s dropping to $69 \%$, followed by an increase in the last decade up to $73 \%$ in 2016.

Moreover, note that after a sudden increase in overall income inequality between 1989 and 1995, as mirrored by the Gini coefficient increasing from 0.31 to 0.40 , income inequality remained rather stable for approximately the entire period (for a thorough analysis of income inequality in Italy over the last decades, see Franzini and Raitano (2016)). The rise in the early 1990s is due to the financial crisis (more precisely a foreign exchange speculative crisis) that occurred in 1992 (Fratianni and Artis, 1996). This crisis was due to a loss of confidence among foreign investors who, after having acquired shares of public debt for several years, speculated against the Italian lira. As shown in Table 2, the 1992 crisis mainly affected the bottom 50\% of the distribution, which lost $10 \%$ of its labor share of income between 1989 and 1995. In contrast, the top 10\% benefited from the crisis, as their labor income share increased in the same period from $15 \%$ to $19 \%$.

Overall, the trends depicted in Tables 1-2 convey a novel lesson about the Italian economy: a structural change in the composition of individuals' income has taken place over the last three decades. In other words, the poor is less of a laborer and more of a 
capital income earner in 2016 with respect to 1989, whilst the rich in the same period became less of a capital income earner and more of a labour income receiver. More precisely, the top $50 \%$ of the income distribution has seen its share of capital income decrease and, at the same time, its share of labor income increase. In 2016, the top 50\% of the income distribution owned $83 \%$ of capital income, in contrast to 1989 , when it owned approximately $95 \%$. The opposite dynamics has taken place at the bottom $50 \%$ of the income distribution, where the share of capital income has increased and the share of labor income decreased.

In light of the evidence shown in Tables 1 and 2, several fundamental questions arise. How can we precisely measure the dynamics of the income composition in Italy? While the Gini coefficient is a measure capable of synthesizing the overall dynamics of income inequality, is there a tool to jointly analyze the dynamics of the two income components across the income distribution? What can we learn from such an investigation, and what policy recommendations can we formulate accordingly? This paper attempts to provide answers to all of these questions.

To this end, we adopt a methodology recently developed by Ranaldi (2020) to study the evolution of income composition inequality in Italy between 1989 and 2016. As proposed by Ranaldi (2020), income composition inequality can be measured through the Income Factor Concentration (IFC) index. Whenever two income sources are concentrated in the hands of the top (e.g., capital income) and bottom (e.g., labor income) of the income distribution, the IFC index indicates a high degree of income composition inequality. By contrast, the IFC index signals a low degree of income composition inequality when the two income sources are equally shared across the income distribution, given the overall levels of income inequality and factor shares.

A high degree of income composition inequality entails a strong link between the functional and personal distributions of income. The underlying intuition is explained as follows: when the rich own all of the capital income in the economy, an increase in the capital income share will boost the income of the rich, therefore boosting income inequality in the population. The contrary situation of a weak link between the functional and personal distributions of income holds true under a low degree of income composition inequality. In the latter case, a change in the factor shares of income will not significantly influence the level of inequality in the population.

By applying this method to the case of Italy, we show that income composition inequality, and therefore the link between the functional and personal distributions 
of income, decreased steadily between 1989 and 2016. This result, which is robust to different definitions of capital and labor income, has two major implications.

[1] The first implication is that fluctuations in the total factor shares of income are having an increasingly weaker impact on income inequality in Italy. In other words, the fraction of the variance of the Gini coefficient explained by the change in factor shares has been decreasing.

[2] The second implication is that Italy has moved in recent decades from a classbased society, in which class and ownership of factor income coincide (workers owning labor income and capital owners receiving capital income), to a multiple sources of income society, in which class and ownership of factor income no longer overlap. In other words, the poor became less of a laborer and the rich less of a capitalist. Furthermore, we show that Italy has become more of a home-owning society but not a society where income from self-employment has become less associated with high income levels overall.

In parallel with the empirical findings, this article conceptualizes a rule of thumb for policy makers seeking to effectively reduce income inequality in the long run. The degree of income composition inequality, as measured by the IFC index, becomes a key variable for the design of effective redistribution policies. Specifically, the rule of thumb relates the fluctuations in total factor shares and the level of income composition inequality to the specific income source to be redistributed. In other words, we claim that when the policy maker's expectation regarding the sign of the variation in factor share $z$ coincides with her expectation regarding the sign of income composition inequality, it is preferable to redistribute source $z$ to reduce inequality in the long run.

This paper is structured as follows. Section 2 introduces the academic literature that we build upon. Section 3 presents the method we employ and the data in more detail and Section 4 shows the main results. Section 5 traces the policy implications of our study and Section 6 concludes the paper.

\section{Background and related literature}

In recent years, and with increased impetus following the pioneering study of Piketty and Zucman (2014), the dynamics of factor income shares are again the subject of economists' attention given their potential effects on the level of personal income inequality (Atkinson, 2009, Glyn, 2011) and thereby on macroeconomic variables. As 
Atkinson (2009) puts it, one of the three reasons to study factor shares is "to make a link between incomes at the macroeconomic level (national accounts) and incomes at the level of the household". This statement is in line with the rationale behind this work, which aims to build a bridge between Italian individual-level data on labor and capital income on the one hand and the aggregate factor shares of income in Italy in recent decades on the other.

There is not yet an established consensus in the literature on the form of the relationship between (changes in) the share of factor incomes and (the effect on) income inequality at the aggregate level. Recent empirical work by Bengtsson and Waldenström (2018) seeks to shed light on this relationship for 21 economies going back as far as the 1930s. Bengtsson and Waldenström (2018) argue that the link between factor shares and inequality does not need to be constant over time and across countries. Indeed, they claim that this link can be "contingent on the production technology, the structure of personal incomes or the institutional context, all of which may-and do indeed-change over time". Bengtsson and Waldenström (2018) find evidence of a strong and positive link between factor shares and inequality, although the magnitude varies from country to country. In light of the result of Bengtsson and Waldenström (2018) of a non-constant relationship hinging on institutional factors, our aim is to analyze the underlying dynamics between factor shares and inequality with a focus on the case of Italy. In our view, focusing on a specific country allows us to analyze the dynamics of this relationship at a higher level of accuracy.

On a theoretical level, Milanovic (2017) identifies the two necessary analytical conditions for the "pass-through" or transmission of a change in factor income shares to the aggregate level of inequality. Specifically, these conditions (for the example of capital income) are (i) a high level of concentration of capital income and (ii) a high and positive association between owners of capital income and the overall top income earners. If both conditions apply, then a rise in capital income leads to a greater level of personal income inequality. The case in which top income earners own capital income and labor income is owned at the bottom of the distribution is labeled by Milanovic (2017) as classical capitalism. Further, Milanovic (2017) suggests that to reduce the overall level of income inequality one must deal with diversification of the ownership of capital income, hence breaking down the first condition described above. The resulting ideal-typical social system for which ownership of a specific factor income no longer coincides with class is labeled by Milanovic (2017) as new capitalism. 
On these lines, this paper intends to determine which ideal-typical social system the Italian economy resembles by analyzing the dynamics of income composition inequality from 1989 to 2016. Further, the adoption of the methodology in Ranaldi (2020) allows us to reduce from two to one the necessary conditions for a pass-through from factor shares to income inequality. Specifically, the sign of the IFC index will determine the effect of a change in factor shares on personal income inequality. Finally, our work relates to the policy proposal of Milanovic (2017) of reducing the concentration of the factor income whose share is increasing by proposing a rule of thumb that identifies the specific income source to be redistributed to reduce overall income inequality in the long run.

In a related study of labor shares and income inequality in Italy during the Fascist period, Gabbuti (2020) provides novel estimates and confirms that the relationship between trends in functional and personal income distribution varies over time, adding that "the Italian case reveals that factor shares offer great, complementary insights in the historical analysis of inequality, reflecting fundamental changes in the economy and society". To complement the historical analysis by Gabbuti (2020), this paper focuses on the relationship between factor shares and income inequality over the last three decades, aiming to show why a thorough analysis of the dynamics of income composition inequality delivers lessons and stylized facts that aggregate estimates of income inequality fail to provide.

\section{Methodology and data}

This section introduces both the method and data that we employ. To assess the link between the functional and personal distributions of income, we follow the method proposed by Ranaldi (2020), who analytically defines the concept of income composition inequality in an effort to estimate the extent to which the composition of income is unequally distributed across the population. The income composition is unequal whenever two sources of income (e.g., capital and labor) ${ }^{2}$ are separately owned by the top and bottom of the income distribution (or vice versa). On the other hand, there is equality of income composition whenever each individual owns the same population shares of the two income sources.

\footnotetext{
${ }^{2}$ In what follows, we exclusively deal with these two sources, although the method can be applied to any pair of sources whose sum equals total income or, rather, total wealth.
} 
The concept of income composition inequality allows to analyze the extent to which changes in factor shares and aggregate income inequality are intertwined. Whenever income composition inequality is high, capital income ends up in the hands of the wealthiest individuals. In this context, an increase in the capital share increases the level of overall income inequality by boosting the income of the wealthy. Therefore, under a high level of income composition inequality, the link between the functional and personal distributions of income is strong. The opposite situation holds true when income composition inequality is low.

To measure income composition inequality, Ranaldi (2020) analytically defines the IFC index. The IFC index is constructed by means of the concentration curves for each income source. These curves are the cumulative distributions of income sources across the total income distribution, hence with individuals being indexed by their income rank and not by their capital or labor income rank. These curves cumulate an income source up to the level of the total factor share (which is less than 1) and not to 1, as is the case for the more standard concentration curves developed by Kakwani (1977a,b). The area below the concentration curve for an income source can be considered a proxy for the level of concentration for the specific income source at the top, or at the bottom, of the income distribution. When this area is large, the income source is concentrated primarily at the bottom of the income distribution, while when the area is small, the source is concentrated at the top.

A graphical representation of the concentration curves for Italy in 1989 is illustrated in Figure 1.

\section{Insert Figure 1 here}

Figure 1 shows the concentration curve for capital income and the related zero- and maximum-concentration curves. Alternatively, one can plot the concentration curve for labor income with the related zero- and maximum-concentration curves. Recall that the sum of the two concentration curves results in the Lorenz curve for total income, which is the red line in Figure 1. Although each concentration curve is associated with a specific zero- and maximum-concentration curves, the choice of focusing on one curve affects solely the narrative of the subject matter. In the following analysis, we will focus on the concentration curve for capital income.

By introducing both the zero- and maximum-concentration curves, which mirror the conditions of zero and maximum inequality in income composition, respectively, 
Ranaldi (2020) constructs the IFC index. The IFC index is defined as the area given by the difference between the concentration curve for the income source and the zeroconcentration curve, suitably normalized. Formally, if we denote the area given by the difference between the zero-concentration curve and the concentration curve for capital by $\mathscr{A}$ and the difference between the zero-concentration curve and the maximumconcentration curve by $\mathscr{B}$, we can define the IFC index (labeled as $\mathscr{I}_{f}$ ) as follows:

$$
\mathscr{I}_{f}=\frac{\mathscr{A}}{\mathscr{B}} .
$$

Another way of expressing this index is as follows: ${ }^{3}$

$$
\mathscr{I}_{f}=\frac{\pi w\left(\tilde{\mu}_{w}-\tilde{\mu}_{\pi}\right)}{\mathscr{B}},
$$

where $\pi$ and $w$ are the capital and labor shares of income, respectively, and $\tilde{\mu}_{w}$ and $\tilde{\mu}_{\pi}$ are the areas of the non-scaled labor and capital concentration curves, respectively. ${ }^{4}$

Interestingly, simple algebra reveals that the derivative of the Gini coefficient, $\mathscr{G}$, with respect to changes in the capital share of income is as follows:

$$
\frac{\partial \mathscr{G}}{\partial \pi}=2\left(\tilde{\mu}_{w}-\tilde{\mu}_{\pi}\right)
$$

Equation 3 states that the sign of the IFC index, which derives from the difference between the areas below the two concentration curves, determines whether an increase in the capital share of income positively or negatively affects the personal income distribution. Thus, the IFC index can be considered a bridge between the functional and personal distributions of income. However, note that the overall change in the total income Gini coefficient is not solely determined by the dynamics of the factor shares. Changes in the structure of the labor market and the introduction of a new redistribution policy are only two of the forces that can influence its dynamics. It is also likely that two different surveys will sample a country's population in two different ways, thereby provoking possible artificial changes in the level of income inequality.

Apart from its technical character, the IFC index also has value from the perspective of political economy. It can be considered a stylized measure of the degree of capitalism of

\footnotetext{
${ }^{3}$ Note that $\mathscr{A}=\pi\left(\tilde{\mu}_{y}-\tilde{\mu}_{\pi}\right)$, where $\tilde{\mu}_{y}$ is the area of the Lorenz curve. The area of the Lorenz curve can be broken down into the sum of the two areas below the concentration curves for capital and labor; hence, $\tilde{\mu}_{y}=\pi \tilde{\mu}_{\pi}+w \tilde{\mu}_{w}$, and we can easily find that $\mathscr{A}=\pi w\left(\tilde{\mu}_{w}-\tilde{\mu}_{\pi}\right)$.

${ }^{4}$ The two areas $\tilde{\mu}_{w}$ and $\tilde{\mu}_{\pi}$ should be multiplied by $w$ and $\pi$, respectively, to obtain the areas of the concentration curves as in Ranaldi (2020).
} 
a social system or economy. Following the framework proposed by Milanovic (2017), the two extreme values that the index can take coincide with two ideal-typical social systems. Specifically, under maximum income composition inequality, a society can be defined as an example of classical capitalism, characterized by a class of wealthy capitalists and a class of poor workers (or, vice versa, a class of wealthy workers and a class of poor capitalists). In contrast, under minimum inequality in income composition, a society can be defined as an example of new capitalism, in which there is no longer any clear mapping between social class and income source. We can therefore state that a particular trend in income composition inequality provides us with novel insights into the form of capitalism towards which a society converges.

As discussed in Ranaldi (2020), the income factor concentration index fills a gap in the literature on the technical assessment of the relationship between the functional and personal distributions of income. Milanovic (2017) adopts the correlation coefficient between capital and total income to study the elasticity of the interpersonal income Gini coefficient to changes in the capital income share. This metric may act as an intuitive and simple measure of such link, although it does not formally determine the condition of the transmission of changes in the functional distribution into income inequality, as does the sign of the IFC index.

From a different perspective, Atkinson and Bourguignon (2000), Atkinson (2009) approach the measurement of this link by decomposing the squared coefficient of the variation in income, here adopted as a measure of income inequality, into the marginal contributions of the labor and capital income. However, they do not provide summary statistics capable of precisely capturing the strength of the link. Instead, Atkinson and Lakner (2017) study the association of capital and labor income at the top by constructing a rank-based measure of association, which is a discrete approximation of the copula density. However, this interesting statistic does not precisely address the issue of the relationship between the functional and personal distributions of income. Indeed, it is rather difficult to determine the joint distributions of capital and labor under which the strength of the link is minimal and maximal.

The IFC index is also different from the pseudo-Gini coefficient proposed by Fei et al. (1978), Pyatt et al. (1980). As discussed by Ranaldi (2020), the pseudo-Gini coefficient cannot act as a measure of the link between the functional and personal distributions of income. In fact, if we were to consider the pseudo-Gini coefficient of capital income, this metric would be zero when all of the individuals in the population earned 
the same amount of capital income. In such a scenario, an increase in the capital share of income would result in an equal increase of the absolute level of the capital incomes of all individuals. Such an increase would therefore make the poor people better off and the rich people worse off by reducing income inequality in the society instead of leaving it unaffected.

\subsection{Data}

At this point in the analysis, we introduce the data employed and the definitions of capital and labor that we adopt. To compute the IFC index, we use the Survey of Household Income and Wealth $(S H I W)$ provided by the Bank of Italy. ${ }^{5}$ The survey covers 8274 households composed of 25150 individuals and 13864 income-earners distributed over approximately 300 Italian municipalities. This survey has been carried out since the 1960s, although information concerning returns on financial assess has only been available since 1989 (see Brandolini et al. (2018) for further information). Therefore, our analysis ranges from 1989 to 2016. The surveys are available every two years, with a two-year gap between 1995 and 1998. The unit of analysis the we adopt is the individual.

The type of income provided by the Bank of Italy is net disposable income, including four sources: (i) payroll income, (ii) pensions and transfers, (iii) net self-employment income and (iv) property income. All of these sources can be further decomposed. ${ }^{6}$ Below, we adopt a single definition of capital and labor income, whereas in Appendix A, we will run the same analysis under different definitions of the two sources.

Capital income is defined as the sum of property income $\left(Y_{p r}\right)$ and the capital component of net self-employment income $\left(Y_{s \pi}\right)$. Formally:

$$
\Pi=Y_{p r}+Y_{s \pi} .
$$

The main definition of labor income we adopt includes payroll income $\left(Y_{p a}\right)$ and the labor component of self-employment income $\left(Y_{s w}\right)$. Since pensions and transfers are

\footnotetext{
${ }^{5}$ The SHIW has been the main source of information about incomes at both the household and individual levels in recent decades.

${ }^{6}$ Payroll income is composed of net wages and salaries and fringe benefits, while pensions and net transfers comprise pensions, arrears, financial assistance scholarships, alimony payments and gifts. Net self employment income is computed as the sum of self-employment income and entrepreneurial income, while property income is the sum of income from real estate and financial assets. Income from real estate includes actual rents and imputed rents, while income from financial assets includes interest on deposits, interest on government securities and income from other sources.
} 
excluded in the baseline definition, we drop pensioners in the database. Formally, we can write:

$$
W=Y_{p a}+Y_{s w} .
$$

As the Bank of Italy does not furnish the capital and labor components of net selfemployment income, we impute them. To this end, we adopt the imputation strategy proposed by Glyn (2011), which attributes the average payroll income $\bar{Y}_{p a}$ of the entire sample (in every year) to represent the maximum value that the labor income component can take. If individual $i$ 's net self-employment income is less than $\bar{Y}_{p a}$ (i.e., $Y_{s}<\bar{Y}_{p a}$ ), then this quantity is considered the labor component of her net selfemployment income. In contrast, if $i$ 's net self-employment income is greater than $\bar{Y}_{p a}$, then we regard the amount $Y_{s \pi}-\bar{Y}_{p a}$ as the capital component of her net selfemployment income.

It is important to note that this assumption may present several issues. By considering the economy's average labor income as a threshold to determine the capital and labor components of self-employment income, we risk underestimating the capital component for those sectors in which the sectorial average payroll income is lower than the economy's average payroll income, and vice versa. The common example is that of the agricultural sector, in which the average labor income is lower than the society's average labor income. Another aspect to consider regarding this decomposition is that it is usually used to decompose macroeconomic rather than microeconomic variables. However, we believe this technique to be more sophisticated than simply attributing two thirds of the self-employment income to its labor component and one third to its capital component. However, in the Appendix we also present a series of income composition inequality in which all the incomes from self-employment are considered as labor income.

Regarding the functional distribution of income, we first derive the capital share of income series from the $S H I W$ data (the red line in Figure 2).

\section{Insert Figure 2 here}

This series is based on our definition of labor (and hence total) income excluding income from pensions and transfers, as explained above. This implies that the corresponding capital/labor share of total income is higher/lower than the capital income 
share that accounts for pensions and transfers in the denominator. The trend for the SHIW capital share series increases over the period $1991-1998$ up to 0.43 and decreases thereafter, reaching in 2016 the levels of the capital share observed in the 1990s.

The series of capital share from the $S H I W$ is compared with the series obtained from the European System of National and Regional Accounts (ESA) to identify possible discrepancies between the two data sources. ${ }^{7}$ The ESA series is represented by the dark line in Figure 2 (labeled ESA 2010). In line with the results obtained by Torrini (2016), the series from ESA confirms that the capital share increased in the 1990s, whereas it decreased from 2000 onward.

The proximity between the red and dark lines in Figure 2 is explained by the fact that both series do not include pensions or transfers in their denominators, which is standard practice in the computation of the official measures of the capital share, normally calculated as one minus the share of employees' compensation in total value added.

\section{Main results}

This section reports the main results of the paper and lays the foundations for the policy recommendations that will be provided in Section 5 . Recall that Tables 1 and 2 indicate that a structural change in the composition of individual incomes has taken place in Italy over the last three decades: the bottom $50 \%$ has seen its total income becoming increasingly more capital intensive, whereas the top 50\%'s income has become increasingly more labor intensive. The aim of the next subsection is to synthesize these facts in a single summary statistic.

\subsection{Income composition inequality}

We proceed to estimate the degree of income composition inequality in Italy. As illustrated in Section 3, Figure 1 plots a one-year (1989) snapshot of the decomposition of the Lorenz Curve (blue) into the concentration curves for capital (red) and labor

\footnotetext{
${ }^{7}$ We consider the 2010 ESA release. From a technical perspective, we consider the functional distribution of gross value added at factor costs. First, we define capital income as value added minus employee compensation. To account for self-employed workers, we assume, as in Torrini (2016), that their earnings are the same as those of waged employees in all sectors. Specifically, this definition relates to the second series of capital income built by Torrini (2016). In a second step, we split the two components of self-employment income in light of the estimates $Y_{s \pi}$ and $Y_{s w}$ derived from the micro data.
} 
(the latter does not appear in Figure 1 since it can be derived from the other concentration curve, holding the Lorenz curve constant). The concentration curve for capital lies below the zero-concentration curve, indicating that in 1989, capital income was concentrated relatively more at the top of the income distribution with respect to labor income.

For each year in the period 1989 - 2016, we then compute the level of the IFC index, as shown in equation 1 in Section 3. The IFC index is again represented by the ratio between the area given by the difference between the concentration curve for capital and the zero-concentration curve $(\mathscr{A})$ and the area between the zero-concentration curve and the maximum-concentration curve $(\mathscr{B})$. Figure 3 graphically conveys the main result of the paper by plotting the 1989 - 2016 series of the IFC index, our measure of the degree of income composition inequality in Italy.

\section{Insert Figure 3 here}

This result can be summarized as follows. Italy experienced a falling degree of income composition inequality throughout the period $1989-2016$ from a level of 0.66 to approximately 0.3. As the Appendix A shows, this result is robust to different definitions of capital and labor income. As shown in Figure 3, income composition inequality follows a radically different trend than that of the Gini coefficient. This is because the IFC index highlights a different dimension of inequality than that summarized by the Gini coefficient. In other words, the evidence that Italy has experienced falling inequality in the composition of individual incomes is not evident from standard inequality measures.

A low degree of income composition inequality indicates that, on aggregate, the two sources of income are owned in equal shares across the income distribution, given the total level of income inequality and of the factor shares. In other words, representing Italy in 2016 as a society in which social classes and sources of income perfectly coincide (a society of poor laborers and rich capitalists) is not in line with the evidence in Figure 3. Italy is gradually becoming a society in which a larger share of individuals earns multiple sources of income.

We now turn to the implications for the linkage between the functional and personal income distributions in Italy. ${ }^{8}$ To what extent have changes in the factor income shares

\footnotetext{
${ }^{8}$ Additional analysis of this aspect is provided in Appendix B.
} 
(as plotted in Figure 2) been transmitted into the level of personal income inequality? Based on the decreasing series of the IFC index, we claim that the strength of the transmission mechanism from changes in factor incomes to changes in the level of personal income inequality weakened throughout the period $1989-2016$.

To clarify this point, recall equation 3 from Section 3. For each percentage increase in the capital share of income, the right-hand side of equation 3 indicates that the contribution to the change in personal income inequality will be given by twice the difference between the areas of the concentration curves ${ }^{9}$.

The decreasing series of Figure 3 implies that the elasticity of personal income inequality to changes in factor income decreased throughout the period. Pinning down the dynamics of the strength of the transmission mechanism from factor income distribution to personal income distribution is in our view an important aspect that previous decompositions (Shorrocks, 1982, Atkinson, 2009) of the variation in personal income inequality did not properly achieve.

Focusing on the determinants of the series of the IFC index in Figure 3, Figures 4 and 5 separately show the series of the areas of the concentration curves for capital and labor, respectively. Recall from Equation 3 that the sign of the IFC index depends uniquely from the difference between the areas below the two concentration curves.

\section{Insert Figures 4-5 here}

The series of the area below the concentration curve for capital (Figure 4) shows an increase in magnitude throughout the period, hence confirming the structural change in the concentration of capital income across the income distribution (from the top 50\% to the bottom 50\%) shown in Table 1.

In contrast, the series of the area of the concentration curve for labor (Figure 5) decreased throughout the period, confirming the structural change in the concentration of labor incomes across the income distribution (here from the bottom 50\% to the top $50 \%$ ) shown in Table 2.

Jointly, the difference between these two areas (the term $\tilde{\mu}_{w}-\tilde{\mu}_{\pi}$ in 3) steadily decreases throughout the period under analysis, explaining the falling degree of the IFC

\footnotetext{
${ }^{9}$ Recall further that the actual series of the Gini coefficient is not determined solely by the dynamics of the factor shares; hence, the evidence in Figure 3 (a stable level of income inequality from the early 1990s onward) might be a net effect of a set of different forces. Regardless of this limitation, we can safely argue that the degree to which changes in the capital income shares yield an increase in the level of income inequality has been steadily decreasing for the Italian economy.
} 
index shown in Figure 3.

\subsection{Factor income components}

Additional insights can be gained by examining the areas of the concentration curves for each of the factor income components. We take a closer look at the way each capital and labor income component evolved between 1989 and 2016.

\subsubsection{Capital income components}

To start with some descriptive statistics, Table 3 refers to the evolution of the distribution of the capital component of self-employment income. Clearly, this component has gradually moved from the bottom $90 \%$ to the top $5 \%$ of the income distribution.

Table 3: Capital component of self-employment income

\begin{tabular}{cccccccc}
\hline \hline Income group & 1989 & 1995 & 2000 & 2004 & 2008 & 2012 & 2016 \\
\hline \hline $0-50 \%$ & $3 \%$ & $3 \%$ & $3 \%$ & $1 \%$ & $2 \%$ & $3 \%$ & $3 \%$ \\
$50-90 \%$ & $33 \%$ & $33 \%$ & $33 \%$ & $24 \%$ & $31 \%$ & $26 \%$ & $25 \%$ \\
$90-95 \%$ & $15 \%$ & $15 \%$ & $13 \%$ & $12 \%$ & $15 \%$ & $13 \%$ & $14 \%$ \\
$95-100 \%$ & $48 \%$ & $49 \%$ & $50 \%$ & $62 \%$ & $51 \%$ & $57 \%$ & $57 \%$ \\
\hline \hline
\end{tabular}

Table 4 shows the distribution of rental income (capital income from real estate). Differently from the capital component of self-employment income, this income source has moved from the top $50 \%$ to the bottom $50 \%$ of the distribution.

Table 4: Capital incomes from real estate

\begin{tabular}{cccccccc}
\hline \hline Income group & 1989 & 1995 & 2000 & 2004 & 2008 & 2012 & 2016 \\
\hline \hline $0-50 \%$ & $8 \%$ & $14 \%$ & $15 \%$ & $17 \%$ & $16 \%$ & $21 \%$ & $21 \%$ \\
$50-90 \%$ & $44 \%$ & $41 \%$ & $42 \%$ & $44 \%$ & $45 \%$ & $42 \%$ & $41 \%$ \\
$90-95 \%$ & $15 \%$ & $14 \%$ & $15 \%$ & $14 \%$ & $14 \%$ & $13 \%$ & $13 \%$ \\
$95-100 \%$ & $32 \%$ & $30 \%$ & $26 \%$ & $24 \%$ & $24 \%$ & $23 \%$ & $24 \%$ \\
\hline \hline
\end{tabular}

To synthesize the facts from Tables 3 and 4, Figure 6 plots the dynamics of the overall area of the concentration curve for capital from Figure 4 together with those of the two sub-components. Notice that the capital incomes from financial assets are not shown as a stand-alone component in this subsection due to high volatility. 


\section{Insert Figure 6 here}

It is straightforward to infer that the overall increasing area below the concentration curve for capital has been driven primarily by rental income (housing rents). This component led to a steady redistribution of capital income from the top 50\% to the bottom $50 \%$ in Italy throughout the period.

\subsubsection{Labor income components}

We now analyze how the concentration of the two labor income components has evolved across the income distribution over the period considered. Table 5 describes the evolution of payroll income.

The top 50\% saw its share of payroll income increase considerably at the expense of the bottom $50 \%$, whose share decreased by 14 percentage points.

Table 5: Payroll income

\begin{tabular}{cccccccc}
\hline \hline Income group & 1989 & 1995 & 2000 & 2004 & 2008 & 2012 & 2016 \\
\hline \hline $0-50 \%$ & $39 \%$ & $26 \%$ & $29 \%$ & $30 \%$ & $31 \%$ & $24 \%$ & $25 \%$ \\
$50-90 \%$ & $47 \%$ & $54 \%$ & $54 \%$ & $53 \%$ & $52 \%$ & $56 \%$ & $55 \%$ \\
$90-95 \%$ & $6 \%$ & $8 \%$ & $8 \%$ & $8 \%$ & $7 \%$ & $9 \%$ & $8 \%$ \\
$95-100 \%$ & $7 \%$ & $11 \%$ & $9 \%$ & $9 \%$ & $10 \%$ & $11 \%$ & $11 \%$ \\
\hline \hline
\end{tabular}

Finally, the concentration of the labor component of self-employment income remained stable at the lower and higher end of the income distribution, as shown in Table 6 , with the exception of the middle class that lost a fraction of $4 \%$ of self-employment income.

Table 6: Labor component of self-employment income

\begin{tabular}{cccccccc}
\hline \hline Income group & 1989 & 1995 & 2000 & 2004 & 2008 & 2012 & 2016 \\
\hline \hline $0-50 \%$ & $32 \%$ & $38 \%$ & $31 \%$ & $27 \%$ & $27 \%$ & $32 \%$ & $33 \%$ \\
$50-90 \%$ & $44 \%$ & $41 \%$ & $44 \%$ & $45 \%$ & $45 \%$ & $41 \%$ & $40 \%$ \\
$90-95 \%$ & $10 \%$ & $8 \%$ & $9 \%$ & $11 \%$ & $11 \%$ & $9 \%$ & $11 \%$ \\
$95-100 \%$ & $13 \%$ & $12 \%$ & $14 \%$ & $16 \%$ & $15 \%$ & $16 \%$ & $15 \%$ \\
\hline \hline
\end{tabular}


To synthesize the facts from Tables 5 and 6, Figure 7 plots the area of the concentration curve for labor (from Figure 5) together with its two components.

\section{Insert Figure 7 here}

We observe similar decreasing trends for the three curves, confirming that labor incomes have shifted partially from the bottom to the top of the income distribution. In particular, it appears that payroll income has been the major driver of the decrease in the area of the concentration curve for labor, in line with the evidence from Table 5 of a significant shift in payroll income from the bottom 50\% to the top 50\%.

\section{Income composition inequality and redistribution}

This section builds on the empirical analysis of the previous sections, to clarify how a better understanding of the linkage between the functional and personal distributions of income can enhance the effectiveness of classic redistribution policies in terms of inequality reduction.

Imagine an economic policy maker seeking to reduce income inequality to maximize social welfare. To that end, she designs a classic redistribution (income taxation and transfer) policy. We argue that while a classical redistribution policy does not necessarily require the policy maker to know the current (and expected future) level of income composition inequality, the same is not necessarily true if the policy is intended to be effective in the longer run. To grasp the concept behind this statement, we introduce the following stylized example (a simple model related to this section is developed in Appendix C).

Consider two countries, labeled Italy 1 and Italy 2 for simplicity. Italy 1's population is composed of workers earning payroll income, the self-employed earning selfemployment income, capital owners earning property income, and a group of pensioners and unemployed individuals earning pensions and transfers. In contrast, Italy 2's population comprises only workers, the self-employed and capital owners, making the absence of pensioners and unemployed individuals in Italy 2 the only difference between the two countries. For simplicity, assume that the pension and transfer system is financed solely by income tax revenues and hence that the government maintains a balanced budget in each period. Specifically, one can assume that, for instance, the government progressively taxes the average total income at the top of the distribution 
and transfers the tax revenues to the poor and elderly in the form of income transfers and pensions. For the sake of simplicity, time index $t=1$ symbolizes the current period or the short run, whereas $t=2$ represents the longer run.

First, we report comparative statistics of the two countries. Clearly, at $t=1$, the level of income inequality would be lower in Italy 1 than in Italy 2 due to the equalizing effect produced by the Italian pension and transfer system. However, at $t=1$, the level of income composition inequality in Italy 1 would be higher than that in Italy 2 , as the introduction of pensioners and unemployed individuals boosts the concentration of capital at the top (since pensioners and the unemployed receive a limited amount of capital income) and that of labor at the bottom of the income distribution (pensions and net transfers count as labor income that is targeted mainly to the poor).

Now, let us turn to the core of our example. The policy maker of Italy 1 expects the effect of her redistribution policy (which implied lower inequality than Italy 2 at $t=1$ ) to also be in place in the longer run, namely, at $t=2$. However, she is unaware of the role played by income composition inequality in the case of a shift in the factor shares of total income (our exogenous shock in this stylized example). Assume that, ceteris paribus, the capital income share in the economy increases by $x \%$ points from $t=1$ until $t=2$. Because the term $2\left(\tilde{\mu}_{w}-\tilde{\mu}_{\pi}\right)$, which is the exact elasticity of changes in the capital share of income to changes in personal income inequality, is lower for Italy 2 (due to its lower degree of income composition inequality), such an increase in the capital share will not have a significant impact on the level of income inequality for Italy 2 . In contrast, the same increase in the capital share will substantially increase the Gini coefficient in Italy 1 at $t=2$ due to a higher level of the elasticity of changes in the factor income distribution to the personal income distribution. As a consequence, the difference in the level of inequality between the two countries at $t=1$ will be reduced or eventually inverted.

As an illustration, assume that elasticity $2\left(\tilde{\mu}_{w}-\tilde{\mu}_{\pi}\right)$ equals 0.3 in Italy 1 and 0.1 in Italy 2 at time $t=1$, with Gini coefficients of 0.35 for Italy 1 and 0.55 for Italy 2. Imagine then that the capital income shares in both economies grow by 10 percentage points from $t=1$ until $t=2$. How will this affect the level of income inequality in the next period? Knowledge of the elasticity $2\left(\tilde{\mu}_{w}-\tilde{\mu}_{\pi}\right)$ allows us to claim that the same increase in the capital share of income in the two countries will hamper income inequality at time $t=2$ three times more in Italy 1 than in Italy 2 . In other words, the positive variations in the Gini coefficient will be $3 \%$ for Italy 1 and $1 \%$ for Italy 2 , reducing the effect of the 
redistribution policy designed in the previous period.

Although this example obviously oversimplifies reality, it helps to clarify the roles that both income composition inequality and the fluctuations in the factor shares have in affecting income inequality in the long run. In practice, to avoid the emergence of a scenario like that depicted in the example, the policy maker should identify at $t=1$ the correct type of income source to redistribute. The following proposition provides a simple rule of thumb that the policy maker should adopt to do so:

Proposition 5.1. If the expected sign of the factor share $z$ 's variation at $t+k$ coincides with the expected sign of $\mathscr{I}_{f}(z)$ over the interval $[t, t+k]$ (i.e., $\mathbb{E}\left(\operatorname{sign}\left(z_{t+k}-z_{t}\right)\right)=\mathbb{E}\left(\operatorname{sign}\left(\mathscr{I}_{f,[t, t+k]}(z)\right)\right)$, with $z=\pi, w)$, then it is preferable to redistribute source $z$ to reduce inequality in the long run.

The intuition behind this proposition is as follows. As long as the level of income composition inequality is positive at $t=1$ (e.g., capital income being concentrated relatively more at the top of the distribution than labor income is) and the capital income share is expected to rise in the coming years up to $t=2$, it is preferable to redistribute income in the form of capital (such as housing or financial assets, depending on their share of capital income) so that the expected increase in the capital income share will not have a strong impact on income inequality. The same will be true in the opposite case: for a negative level of income composition inequality (e.g., labor income being concentrated relatively more at the top of the distribution than capital income is), an expected increase in the labor share in the coming years will signal that labor income must be redistributed to reduce inequality in the longer run. For the sake of completeness, consider two additional scenarios that might arise. Specifically, when the two signs in this proposition differ, the expected change in income source $z$ is already acting in favor of the redistribution of income in the long run. In the latter case, then, knowledge of the degree of income composition inequality does not generate further insights for the policy maker. The four scenarios are summarized in Figure 8.

In summary, we argue that in the event of an expected variation in a given factor share of income, a policy maker should consider the sign of the degree of income composition inequality to design effective redistribution policies. Choosing to redistribute the correct factor share will efficiently and more permanently reduce the burden of income inequality in the economy.

In Appendix C, we develop a model that shows that under incomplete information regarding changes in the functional income distribution and the level of income com- 
position inequality, an inequality-averse social planner can choose a sub-optimal vector of taxes to reduce income inequality in the society.

\section{Concluding remarks}

This paper analyzes the evolution of inequality in income composition in terms of capital and labor income in Italy between 1989 and 2016. We start by highlighting the rise in the fraction of capital incomes accruing to the bottom of the distribution, whilst in parallel the top of the distribution increases its share of labor income.

To summarize this structural change, we focus on a novel measure of income composition inequality, the IFC index introduced by Ranaldi (2020). A falling IFC index between the years 1989 and 2016 in Italy implies a falling degree of income composition inequality in the period considered, which in turns entails that Italy is becoming less and less an economy composed of poor laborers and rich capitalists. This result is robust to the use of different definitions of capital and labor income, as shown in Appendix $\mathrm{A}$, in which we include pensions and transfer and modify the allocation of net self-employment income.

The lower (higher) the degree of income composition inequality is, the weaker (stronger) is the link between movements in factor income shares and personal income inequality. Hence, a falling degree of income composition inequality implies a weaker link between the functional and personal distributions of income. Thereby, our results suggests that fluctuations in the total factor shares of income are having an increasingly weaker impact on income inequality in Italy.

In the second part of this article, we conceptualize a simple rule of thumb that relates fluctuations in the total factor shares and the level of income composition inequality to the specific income source to be redistributed. We argue that in the event of an expected variation in a given factor share of income, a policy maker should consider the sign of the degree of income composition inequality to design redistribution policies with long-term efficacy.

We consider this article to be part of a broader research agenda on the issue of income composition inequality and specifically on the link between factor shares and income inequality. We believe the technical assessment of this link introduces a novel dimension to the study of income distribution.

Understanding the relationship between the macro-level dynamics of economic ag- 
gregates such as the capital and labor shares of income and the micro-level changes in the dispersion of income across the population can further emphasize the political economy character of the issue of income distribution. As stated in Section 5, understanding this link is fundamental to designing effective redistribution policies that pursue a lower level of income inequality in society. As such policies are the responsibility of the incumbent policy maker, the role politics plays in this setting should be considered with greater care in future research than was done in this study. 


\section{References}

Atkinson, A. and Bourguignon, F. (2000). Introduction: Income Distribution and Economics. In Handbook of Income Distribution, volume 1, pages 1-58. Elsevier.

Atkinson, A. B. (2009). Factor shares: the principal problem of political economy? $O x$ ford Review of Economic Policy, 25(1):3-16.

Atkinson, A. B. and Lakner, C. (2017). Capital and labor : the factor income composition of top incomes in the United States, 1962-2006. World Bank Policy Research working paper; no. WPS 8268 , pages $1-43$.

Bengtsson, E. and Waldenström, D. (2018). Capital Shares and Income Inequality: Evidence from the Long Run. The Journal of Economic History, 78(3):712-743.

Brandolini, A., Gambacorta, R., and A., R. (2018). Inequality amid Stagnation: Italy over the Last Quarter of a Century. In Inequality and Inclusive Growth in Rich Countries: Shared Challenges and Contrasting Fortunes, chapter 8. Oxford University Press.

Fei, J. C. H., Ranis, G., and Kuo, S. W. Y. (1978). Growth and the Family Distribution of Income by Factor Components. The Quarterly Journal of Economics.

Franzini, M. and Raitano, M. (2016). Income Inequality in Italy: Tendencies and Policy Implications. In Italy in a European Context: Research in Business, Economics, and the Environment, pages 50-74. Palgrave Macmillan.

Fratianni, M. and Artis, M. J. (1996). The lira and the pound in the 1992 currency crisis: Fundamentals or speculation? Open Economies Review.

Gabbuti, G. (2020). A Noi! Income Inequality and Italian Fascism: Evidence from Labour and Top Income Shares. Oxford Economic and Social History Working Papers Number 177.

Glyn, A. (2011). Functional Distribution and Inequality. The Oxford Handbook of Economic Inequality.

Kakwani, N. C. (1977a). Applications of Lorenz Curves in Economic Analysis. Econometrica, 45(3):719-727. 
Kakwani, N. C. (1977b). Measurement of Tax Progressivity: An International Comparison. The Economic Journal, 87(345):71-80.

Lerman, R. I. and Yitzhaki, S. (1985). Income inequality effects by income source: A new approach and applications to the united states. The Review of Economics and Statistics, 67(1):151-156.

Milanovic, B. (2017). Increasing capital income share and its effect on personal income inequality. In Boushey, H., de Long, B., and Steinbaum, M., editors, After Piketty: The agenda for economics and inequality, pages 235-239. Harvard University Press.

Piketty, T. and Zucman, G. (2014). Capital is Back: Wealth-Income Ratios in Rich Countries 1700-2010 *. The Quarterly Journal of Economics, 129(3):1255-1310.

Pyatt, G., Chen, C.-n., and Fei, J. (1980). The Distribution of Income by Factor Components. The Quarterly Journal of Economics.

Ranaldi, M. (2019). Income composition inequality : the missing dimension for distributional analysis. Université Panthéon-Sorbonne - Paris I.

Ranaldi, M. (2020). Income Composition Inequality. Stone Center on Socio-Economic Inequality Working Paper Series, No.7.

Shorrocks, A. F. (1982). Inequality Decomposition by Factor Components. Econometrica, 50(1):193-211.

Torrini, R. (2016). Labour, profit and housing rent shares in Italian GDP: long-run trends and recent patterns. Occasional Papers (Questioni di economia e finanza) No. 318. 


\section{Appendices}

\section{A Robustness}

In this section, we compute the IFC index for different definitions of labor and capital income.

IFC2: we consider labor income as the sum of payroll income $\left(Y_{p a}\right)$, the labor component of self-employment income $\left(Y_{s w}\right)$, including now pensions $\left(Y_{p e}\right)$ and transfers $\left(Y_{t r}\right)$. Capital income is defined as the sum of the capital component of self-employment income $\left(Y_{s \pi}\right)$ and property income $\left(Y_{p r}\right)$. Figure 9 shows the trend of the novel series (IFC2) compared to the benchmark series previously shown in Figure 3. The gap between the two series remains roughly constant throughout the entire period, with the exception of the years 2012-2016. Focusing on IFC2, the degree of income composition inequality decreases steadily from just below 0.6 to approximately 0.3 . The introduction of pensions and transfers in the definition of labor income (and of pensioners in the population) has decreased the overall level of income composition inequality. This puzzling result reflects the fact that pensioners, whose average income is at the middle of the distribution, reduces the degree of income composition inequality relatively more than how transfer recipients increase it. It can indeed be noticed that the mean yearly labor income of a pensioners in 2016 was 14, 183 euro, whilst the one of an individual receiving positive transfers income of 10,289 . In addition to that, the $70 \%$ of pensioners belong to the top $50 \%$ of the income distribution, meaning that by introducing this socio-economic group, we increase the relative share of labor income at the top $50 \%$ of the distribution, and hence reduce the overall level of income composition inequality.

IFC3: when we consider self-employment income as labor income only, without hence decomposing it into its labor and capital income components via the Glyn's method, we obtain the series IFC3 (Figure 10). IFC3 entails a decreasing trend of income composition inequality over the period, although this trend is less marked than those of IFC and IFC2. This is due to the fact that about the $80 \%$ of self-employers belong to the top $50 \%$ in terms of income. Hence, when we consider self-employment income as labor income only we increase the share of labor income at the top of the income distribution, and reduce the degree of income composition inequality.

Overall, the three series IFC-IFC2-IFC3 show that regardless of which definition of capital and labor income we adopt, income composition inequality has constantly 
decreased over the last three decades in Italy. 


\section{B Correlation evidence}

In this section, we further document the role played by income composition inequality in shaping the overall dynamics of income inequality as measured by the Gini coefficient $\mathscr{G}$.

In particular, we separately discuss the impact of income composition inequality on income inequality due to its variation and that due to its level.

To provide a more thorough methodological foundation for the following analysis, we adopt the analytical decomposition of income inequality variation proposed in Ranaldi (2019).

This method, which is based on the Lerman and Yitzhaki (1985) decomposition of the Gini coefficient in factor components, affirms that a variation in income inequality can be interpreted as a result of three types of movements: (a) movements in the functional income distribution, (b) movements in the income factor concentration, and (c) movements in income factor inequality. This decomposition suggests that such movements explain a large part of the variance in income inequality.

These three motions are operationalized below by changes in the capital share of income (movement (a) and first term on the right-hand side), changes in the IFC index (movement (b) and the second term) and changes in the Gini coefficient of capital income (movement (c) and the third term).

Because of the limited sample size (12 observations), this ordinary least squares (OLS) exercise is solely meant to provide the reader with correlation evidence and additional points of discussion for a comprehensive analysis of the dynamics involved.

The first specification we consider is the following:

$$
\Delta \mathscr{G}=\alpha_{1} \times \Delta \pi+\alpha_{2} \times \Delta \mathscr{I}_{f}(\boldsymbol{\pi})+\alpha_{3} \times \Delta \mathscr{G}_{\pi}+\epsilon,
$$

where $\Delta$ refers to absolute changes (first differences), $\mathscr{G}_{\pi}$ is the Gini coefficient of capital income, and $\epsilon$ is the iid error term.

The OLS results are shown in column (1) in Table 7: 
Table 7: Correlation evidence

\begin{tabular}{lcc}
\hline & $(1)$ & $(2)$ \\
Variables & $\Delta \mathscr{G}$ & $\Delta \mathscr{G}$ \\
\hline$\Delta \pi$ & 0.274 & \\
& $(0.232)$ & \\
$2\left(\tilde{\mu}_{w}-\tilde{\mu}_{\pi}\right) \Delta \pi$ & & $4.065^{*}$ \\
& & $(2.207)$ \\
$\Delta \mathscr{I}_{f}(\pi)$ & $-0.252^{* * *}$ & $-0.238^{* * *}$ \\
& $(0.0591)$ & $(0.0551)$ \\
$\Delta \mathscr{G}_{\pi}$ & $1.526^{* * *}$ & $1.407^{* * *}$ \\
& $(0.236)$ & $(0.228)$ \\
Observations & 12 & 12 \\
\hline \multicolumn{2}{c}{ Standard errors in parentheses. } \\
$* * *$ & p $<0.01,{ }^{* *} \mathrm{p}<0.05, *$ p $<0.1$
\end{tabular}

Note: Correlation evidence between income inequality variation and movements $\mathrm{a}, \mathrm{b}, \mathrm{c}$.

Column (1) in Table 7 shows that while changes in the capital share do not correlate with the variation in income inequality, the changes in income composition inequality and in capital income inequality are correlated. In particular and most important, the variation in income composition inequality is negatively correlated with the variation in income inequality, whereas the variation in capital inequality is positively correlated with it.

We set up an alternative model specification (column 2 in Table 7), in which the absolute change in capital income (movement (a)) is replaced by its product with the elasticity $2\left(\tilde{\mu}_{w}-\tilde{\mu}_{\pi}\right)$, as in equation 3 . This modification can be interpreted as introducing a weight on $\Delta \pi$ that reflects the degree of its condition of transmission. Formally, this modified specification reads:

$$
\Delta \mathscr{G}=\beta_{1} \times 2\left(\tilde{\mu}_{w}-\tilde{\mu}_{\pi}\right) \Delta \pi+\beta_{2} \times \Delta \mathscr{I}_{f}(\pi)+\beta_{3} \times \Delta \mathscr{G}_{\pi}+\epsilon .
$$

The results reported in column (2) of Table 7 show that the newly introduced term $2\left(\tilde{\mu}_{w}-\tilde{\mu}_{\pi}\right) \Delta \pi$ appears to be more highly correlated with the variation in income inequality than $\Delta \pi$ was in the first case. Additionally, $2\left(\tilde{\mu}_{w}-\tilde{\mu}_{\pi}\right) \Delta \pi$ is positively correlated with 
the variation in income inequality, which is consistent with equation 3. In fact, equation 3 predicts that if the IFC index is positive (which is the case here), then an increase in the capital share positively affects the Gini coefficient.

The results from Table 7 highlight how changes in the degree of income composition inequality (movement (b), the second term in both model specifications) correlates with changes in income inequality. Specifically, the negative correlation between the variations in these two variables stresses a very important aspect: the reduction in income inequality caused by redistribution policies designed to transfer income from the top to the bottom of the distribution in the form of labor income is associated with an increase in income composition inequality. This occurs because such policies hamper the degree of concentration of both labor income at the bottom and capital income at the top of the income distribution, as shown by the areas of the concentration curves for capital and labor in Figures 4 and 5, respectively. 


\section{A simple model}

This appendix develops a partial-equilibrium model whose rationale is simply to provide a more thorough explanation of Proposition 5.1. Specifically, we show that under incomplete information regarding changes in the functional income distribution and the level of income composition inequality, an inequality-averse social planner can choose a sub-optimal vector of taxes to reduce income inequality in the society.

For the sake of simplicity, consider an economy composed of 2 agents, A and B, with total incomes $Y_{A}$ and $Y_{B}$, respectively. The total income in the economy is the sum of the capital and labor income, $Y=\Pi+W$. The two agents may hold shares of each income source as follows:

$$
\begin{aligned}
& Y_{A}=\alpha_{A} \Pi+\beta_{A} W, \\
& Y_{B}=\alpha_{B} \Pi+\beta_{B} W .
\end{aligned}
$$

where $\alpha_{A}, \alpha_{B}, \beta_{A}$ and $\beta_{B}$ are the relative shares of capital and labor of each agent, respectively. The utility function of agent $i=A, B$ is given by:

$$
U_{i}(Y)=\log \left(Y_{i}\right)
$$

Assume that the social planner of this society is inequality-averse á la Rawls; hence, she maximizes the following social welfare function (SWF):

$$
\max _{\left\{Y_{A}, Y_{B}\right\}} S W F=\max \min \left\{Y_{A}, Y_{B}\right\}
$$

A baseline and an alternative scenario will be analyzed below.

\section{C.1 Baseline Scenario}

In this baseline scenario, we assume the following: $0<$ Gini $<1 ; \Delta \Pi=0 ; Y_{A}>Y_{B}$; $\alpha_{A}=1, \alpha_{B}=0, \beta_{A}=0$, and $\beta_{B}=1$; hence, $Y_{A}=\Pi>Y_{B}=W$. Income composition inequality is therefore maximal, and no changes in the factor shares will occur between $t=1$ and $t=2$.

Suppose that at $t=1$, the Rawlsian social planner seeks to reduce the positive level of income inequality, although she is unaware of the high degree of income composition inequality in the society. 
Therefore, to reduce income inequality, the Rawlsian social planner finds it optimal to transfer income between agents. This can be formalized by the following maximization problem:

$$
\max _{\left\{Y_{A}, Y_{B}\right\}} S W F=\max \min \left\{Y_{A}, Y_{B}\right\},
$$

subject to the constraint given by the following balanced government budget:

$$
t_{\pi} \Pi+t_{w} W=\Omega
$$

where $\Omega$ represents the value of the redistributive transfer.

This maximization problem ends only when full equality of incomes between agents is achieved. Hence, the SWF is maximal when:

$$
Y_{A}\left(t_{\pi}, t_{w}\right)=Y_{B}\left(t_{\pi}, t_{w}\right)
$$

By solving the maximization problem, we find the following result

$$
\Pi\left(1-t_{\pi}\right)=W\left(1-t_{w}\right) .
$$

The optimal vector of taxes $\mathbf{t}^{*}\left(t_{\pi}, t_{w}\right)$ that solves this problem is not unique. For simplicity, we assume that the Rawlsian social planner intends to redistribute income solely by moving it from the rich to the poor. Hence, by substituting $t_{w}=0$, we find that $\mathbf{t}^{*}\left(t_{\pi}, t_{w}\right)=\left[\frac{\Pi-W}{\Pi} ; 0\right]$.

At time $t=2$, the optimal vector of taxes $\mathbf{t}^{*}$ reduces income inequality, as measured by the Gini coefficient, to 0 . In other words, in the baseline scenario with unchanged factor shares of income, knowledge of the degree of income composition inequality was irrelevant for the social planner.

\section{C.2 Alternative scenario}

In this alternative scenario, we further assume that $\Delta \Pi>0$, and $\Delta W<0$. Hence, changes in the factor shares will occur between $t=1$ and $t=2$, and income composition inequality is still maximal.

At time $t=1$, since the Rawlsian social planner is unaware of the role played by the degree of income composition inequality, she adopts the same redistribution policy described in the baseline scenario, given by the optimal vector of taxes $\mathbf{t}^{*}\left(t_{\pi}, t_{w}\right)=\left[\frac{\Pi-W}{\Pi} ; 0\right]$ and the corresponding transfer $\Omega^{*}{ }^{10}$

\footnotetext{
${ }^{10}$ Note that after the redistribution policy adopted by the social planner, the level of income composition inequality has decreased given that the poor agent has received some capital income. However, the level of income composition inequality remains positive.
} 
At this point, the positive degree of income composition inequality implies that the change in the factor income shares has a substantial effect on income inequality, invalidating the optimality of the specific redistribution policy derived in the baseline scenario.

Indeed, at $t=2$, equality of incomes between agents would be ensured by $\mathbf{t}^{* *}\left(t_{\pi}, t_{w}\right)=$ $\left[\frac{\Pi^{\prime}-W^{\prime}}{\Pi^{\prime}} ; 0\right] \neq\left[\frac{\Pi-W}{\Pi} ; 0\right]=\mathbf{t}^{*}\left(t_{\pi}, t_{w}\right)$ since $\frac{\Pi^{\prime}-W^{\prime}}{\Pi^{\prime}}>\frac{\Pi-W}{\Pi}$. This result invalidates the optimality of the redistribution policy of the baseline scenario. In other words, having knowledge of the degree of income composition inequality in the society has proved to be crucial in determining equality in incomes in the society. 


\section{List of Figures}

1 Concentration Curve for Capital - Italy $1989 \ldots \ldots$. . . . . . . . . . . 34

2 Capital share of income . . . . . . . . . . . . . . . . . 35

3 Income Composition Inequality and Gini coefficient . . . . . . . . . . 36

4 Area of the Concentration Curve for Capital . . . . . . . . . . . . . 37

5 Area of the Concentration Curve for Labor . . . . . . . . . . . . . . . 38

6 Area of the Concentration Curve for Capital - Decomposition by Type . 39

7 Area of the Concentration Curve for Labor - Decomposition by Type . . 40

8 Getting Redistribution Right . . . . . . . . . . . . . . . . . . . . . . . . . 41

9 Income Composition Inequality - Robustness . . . . . . . . . . . . . . . 42

10 Income Composition Inequality - Robustness II . . . . . . . . . . . . . . 43 
Figure 1: Concentration Curve for Capital - Italy 1989

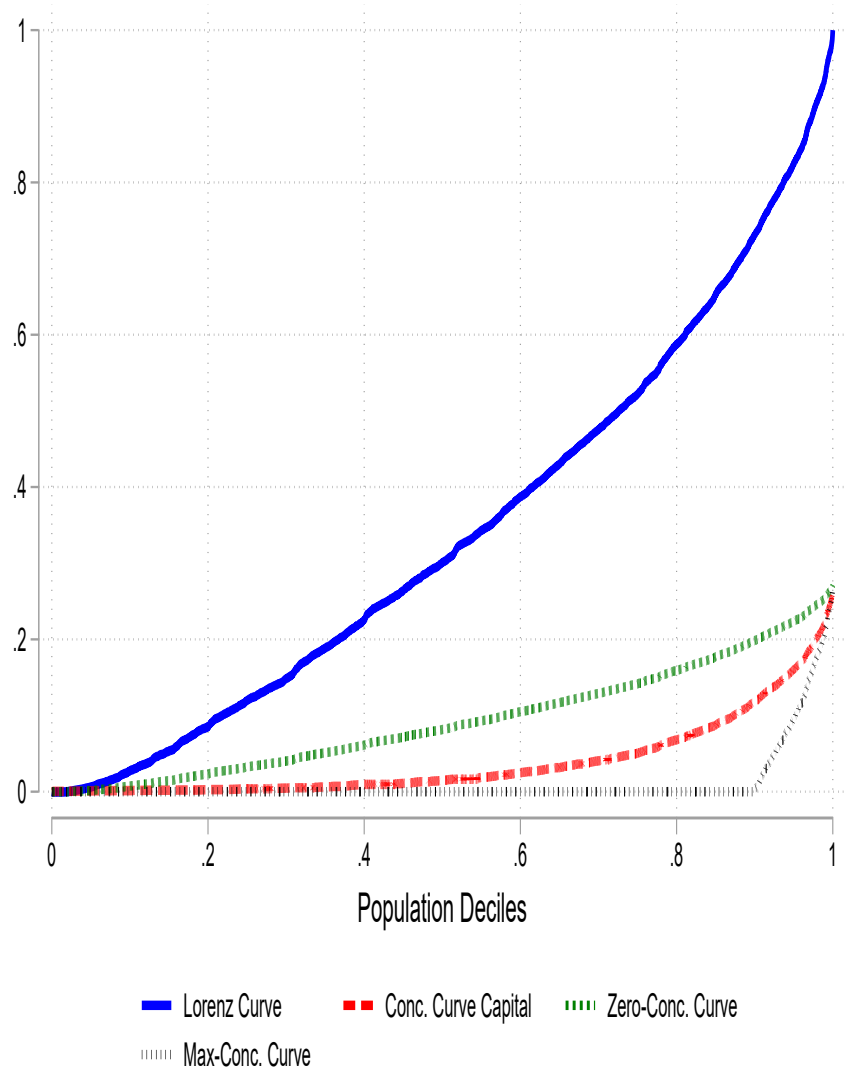

Note: The concentration curve for capital (red line), the zero-concentration curve (green line), the Lorenz curve for income (blue line) and the maximum-concentration curve (black line) for Italy in 1989 are presented using data from the 1989 Survey on Household Income and Wealth (SHIW) carried out by the Bank of Italy. Capital income is defined as the sum of property income and the capital component of net selfemployment income. Labor income is defined as the sum of payroll income and the labor component of mixed income. Both the capital and labor components of self-employment income are imputed following Glyn (2011). Pensioners are excluded from the analysis. 
Figure 2: Capital share of income

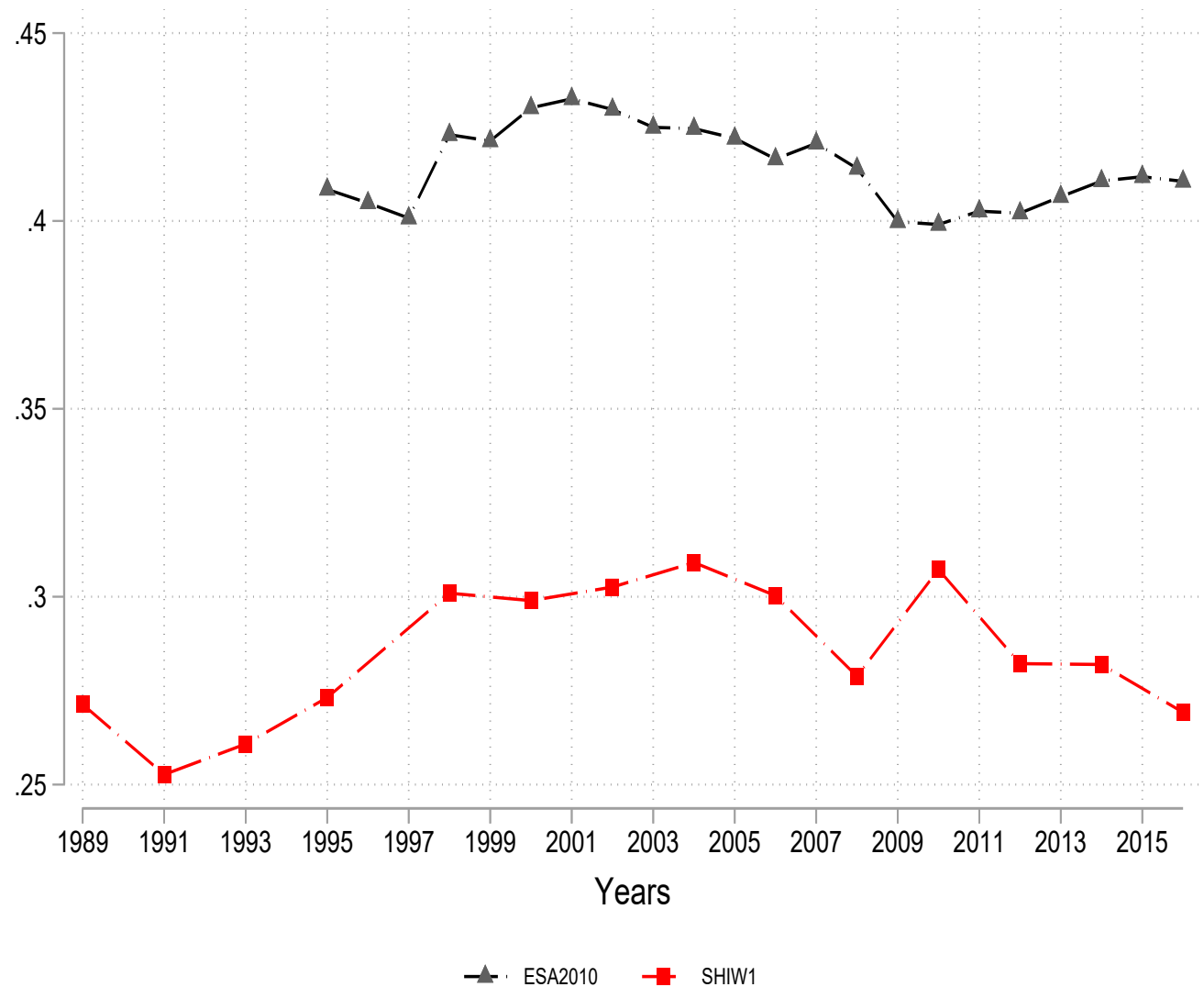

Note: Two series of the capital income share in Italy are presented here. The first series (ESA 2010), which runs from 1995 to 2016, is constructed from the ESA 2010 National Accounts and is calculated as the difference between value added at factor prices minus employee compensation. To account for self-employed workers, we assume that they earn the same as waged employees in all sectors. The second (SHIW 1) series (red line), which covers the period between 1989 and 2016, is built from the Survey of Household Income and Wealth (SHIW) prepared by the Bank of Italy. Total income is the sum of payroll income, net self-employment income and property income. Capital income equals property income plus the capital component of net self-employment income. The latter is imputed following Glyn (2011). Pensioners are excluded from the analysis. 
Figure 3: Income Composition Inequality and Gini coefficient

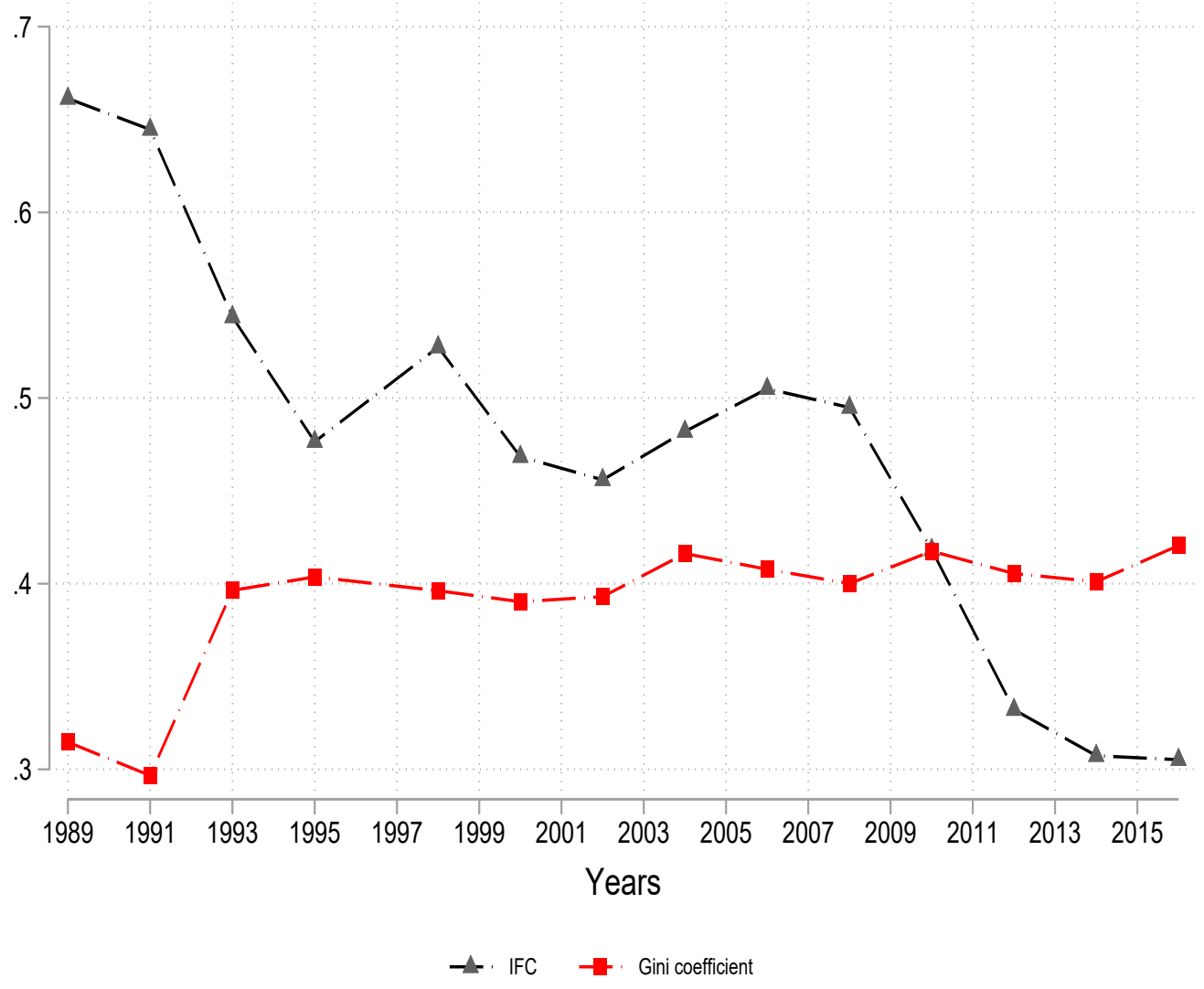

Note: Series of the IFC index and the Gini coefficient constructed using the SHIW data. Capital income is defined as the sum of property income and the capital component of net self-employment income. Labor income is defined as the sum of payroll income and the labor component of mixed income. Total income is the sum of capital and labor income. Both the capital and labor components of self-employment income are imputed following Glyn (2011). Pensioners are excluded from the analysis. 
Figure 4: Area of the Concentration Curve for Capital

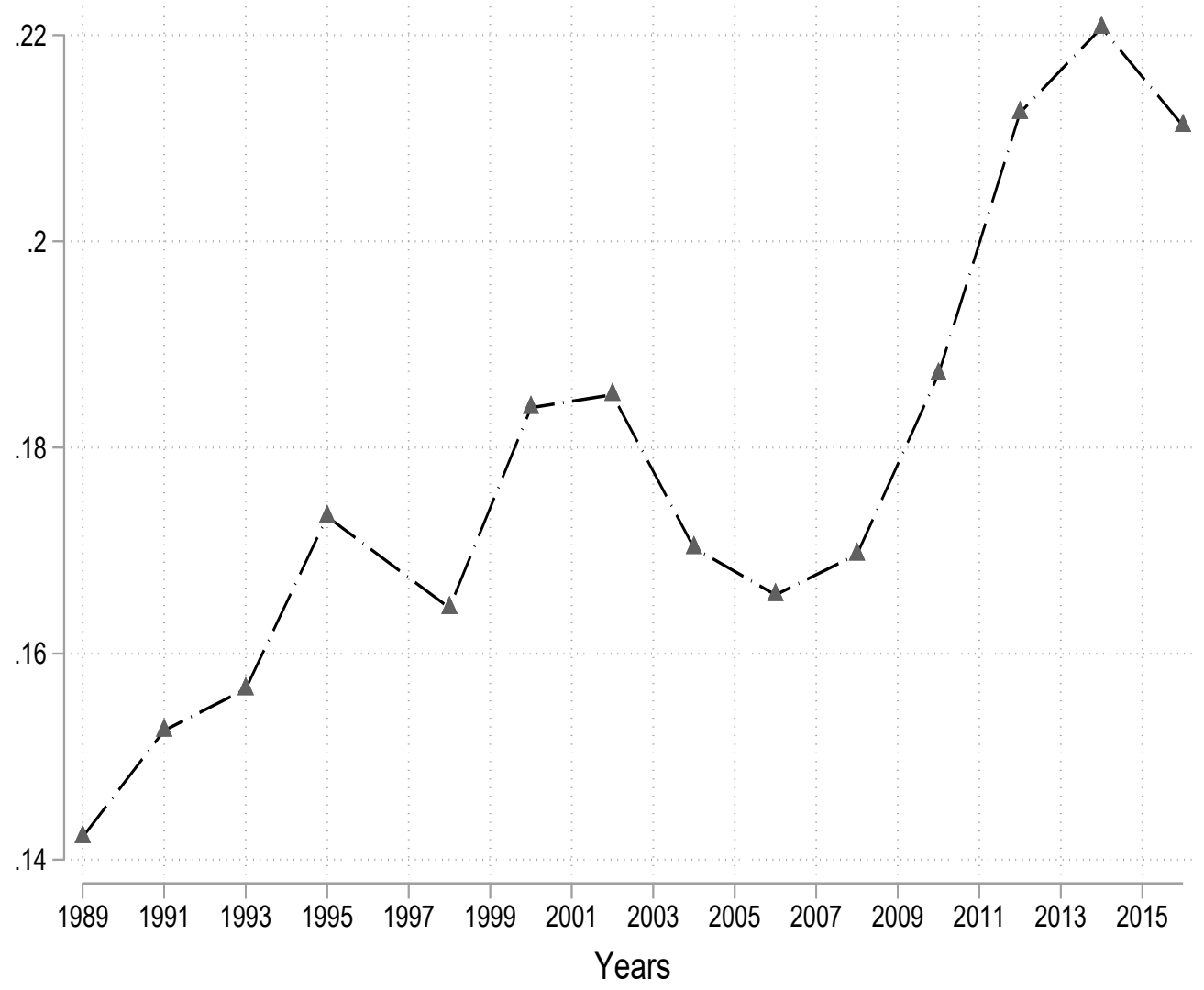

Note: Series of the area of the concentration curve for capital constructed using the SHIW data. Total income is the sum of payroll income, net self-employment income and property income. Capital income equals property income plus the capital component of net self-employment income. The latter is imputed following Glyn (2011). Pensioners are excluded from the analysis. 
Figure 5: Area of the Concentration Curve for Labor

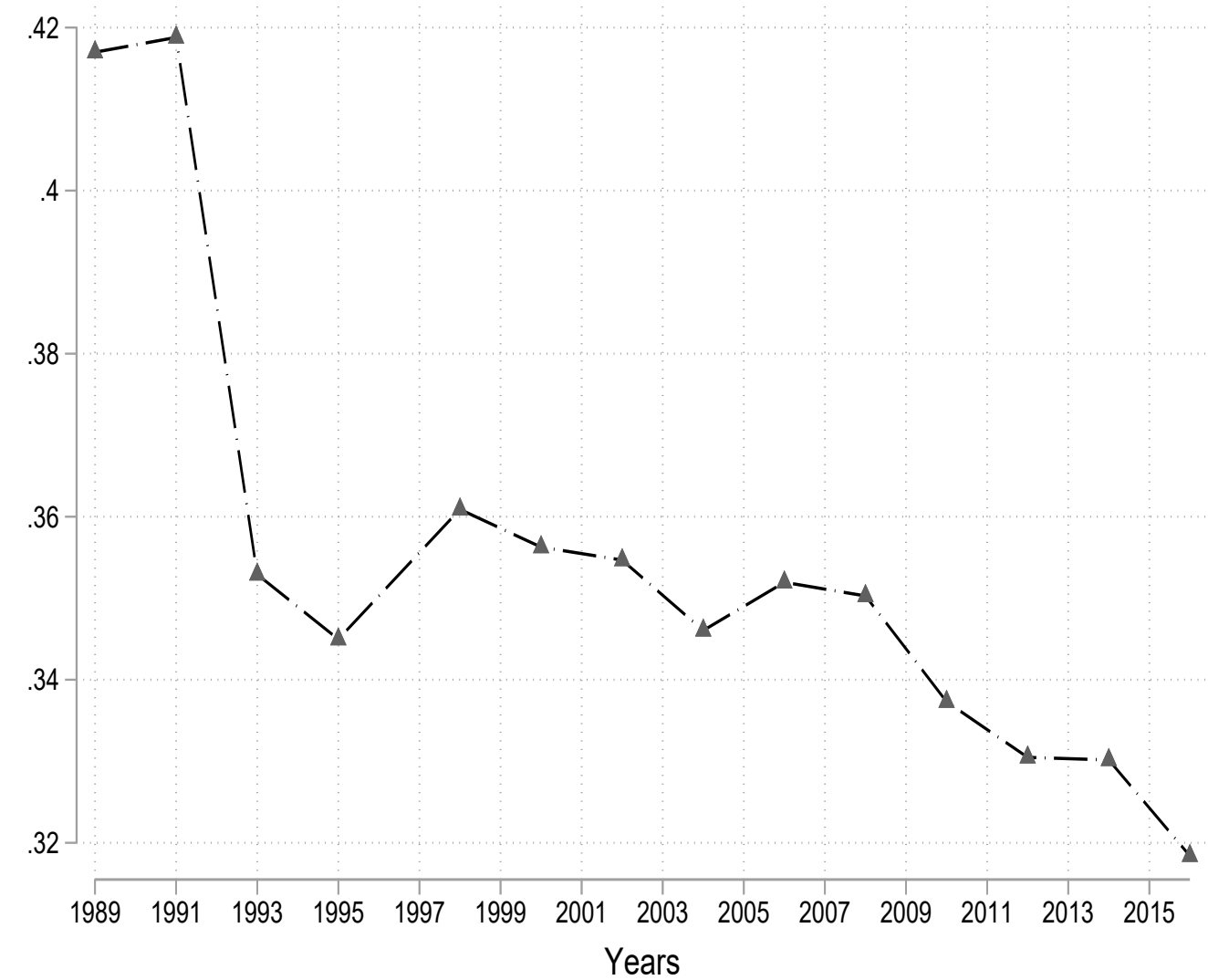

Note: Series of the area of the concentration curve for labor constructed using the SHIW data. Total income is the sum of payroll income, net self-employment income and property income. Labor income equals payroll income plus the labor component of net self-employment income. The latter is imputed following Glyn (2011). Pensioners are excluded from the analysis. 
Figure 6: Area of the Concentration Curve for Capital - Decomposition by Type

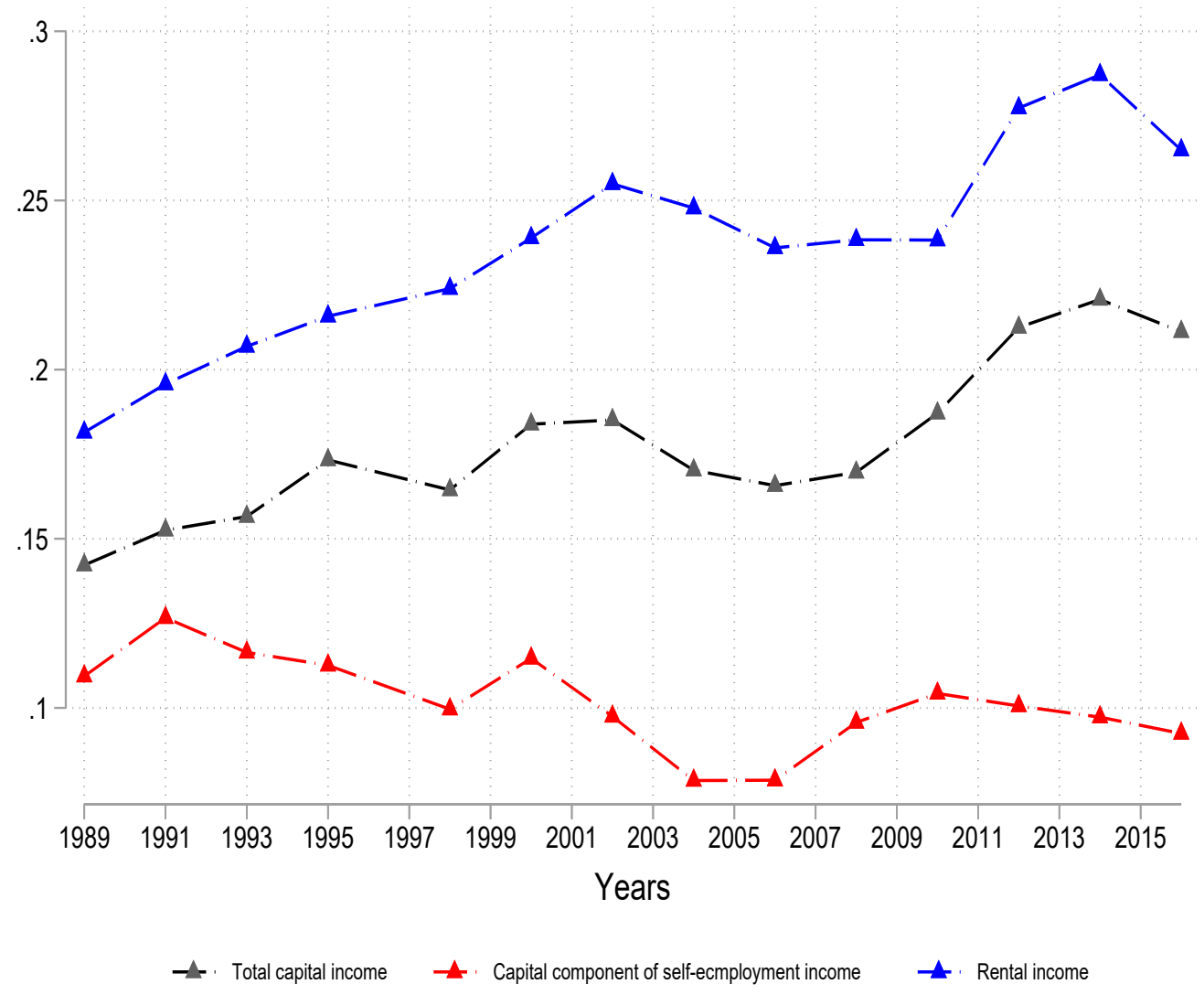

Note: Series of the area of the concentration curve for capital income (black line) and the areas of the concentration curves for the capital component of self-employment income (red line), and real estate (blue line) constructed using the SHIW data. Total income is the sum of payroll, self-employment income and property income. Pensioners are excluded from the analysis. 
Figure 7: Area of the Concentration Curve for Labor - Decomposition by Type

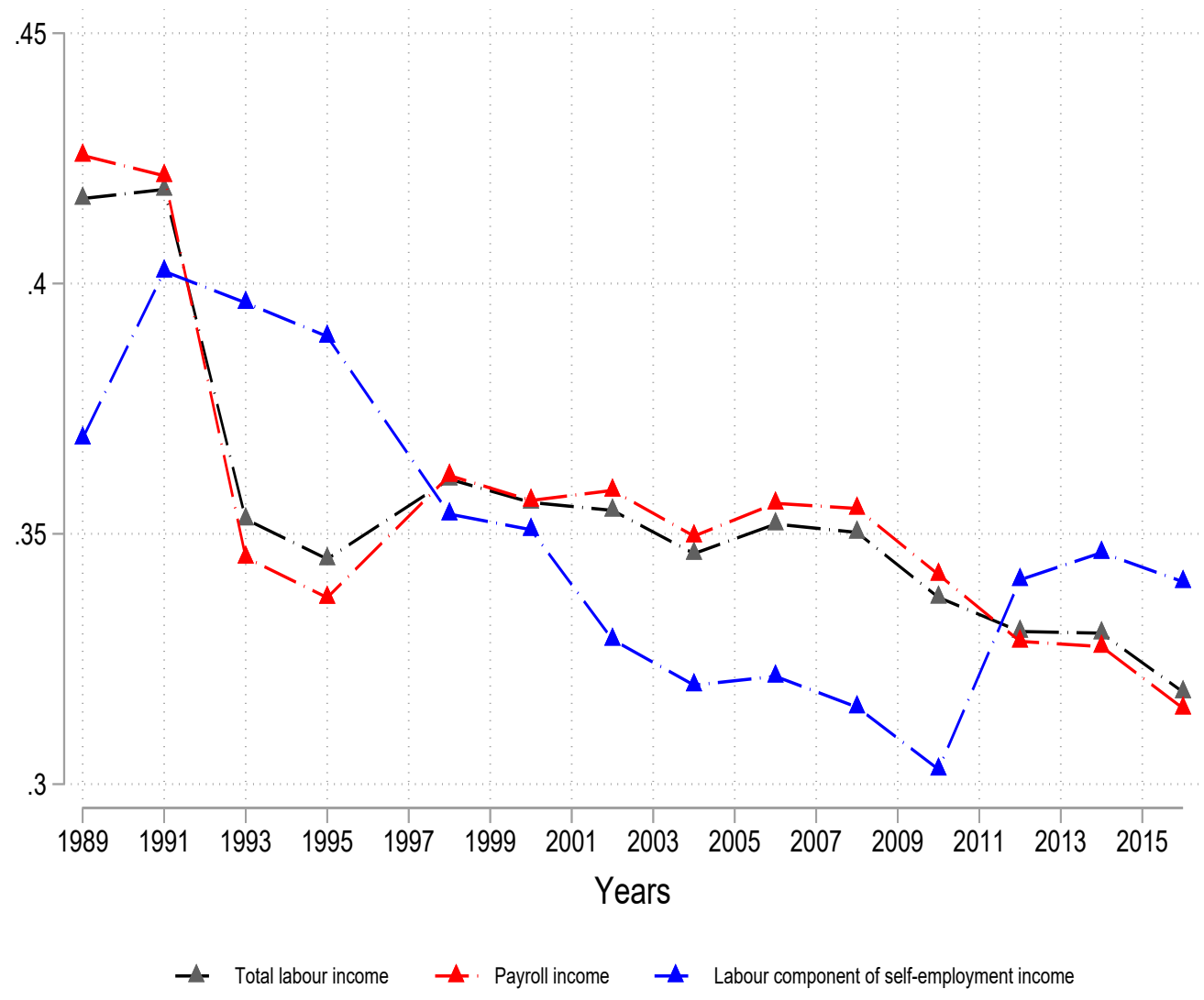

Note: Series of the area of the concentration curve for labor income (black line) and the areas of the concentration curves for payroll income (red line) the labor component of self-employment income (blue line) constructed using the SHIW data. Total income is the sum of payroll, self-employment income and property income. Pensioners are excluded from the analysis. 
Figure 8: Getting Redistribution Right

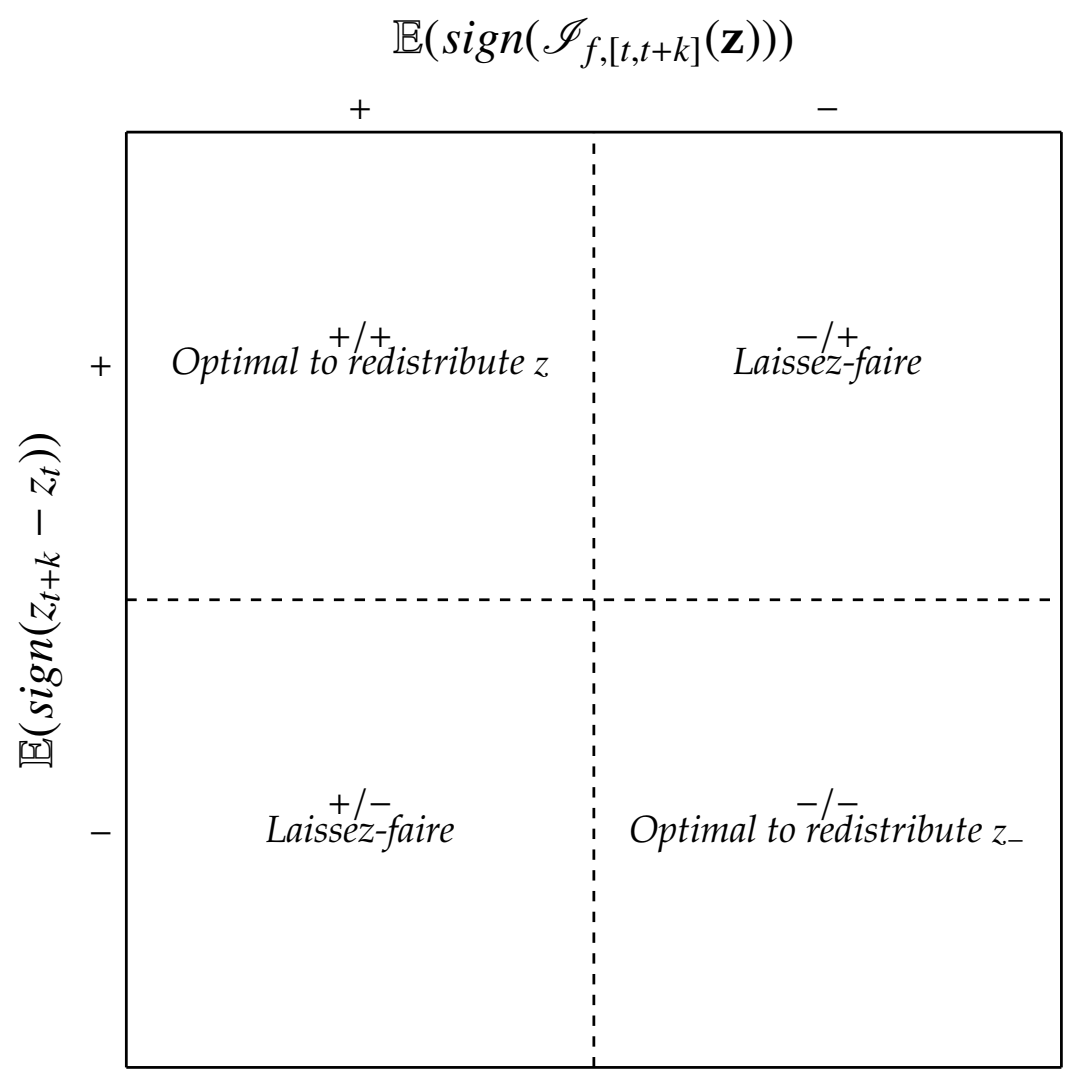

Note: This figure shows the four scenarios behind Proposition 5.1 in Section 5. Scenario 1: As long as the level of income composition inequality (top of the table) is expected to be positive (e.g., capital income is concentrated primarily at the top of the distribution, and labor income is concentrated at the bottom) and the capital income share (on the left of the table) is expected to rise, it is preferable to redistribute income in the form of capital (e.g., housing or financial assets) so that the expected increase in the capital income share will not have a strong impact on income inequality. Scenario 2: This scenario depicts the opposite case. For a negative level of income composition inequality (e.g., capital income mostly accruing at the bottom of the distribution, and labor income accruing at the top), an expected increase in the labor share in the upcoming years will indicate that labor income has to be redistributed to reduce inequality in the longer run. Scenarios 3 and 4: For the sake of completeness, we consider two other scenarios that might arise. When the two signs in the above proposition differ, the expected change in the income source $z$ is already acting in favor of the redistribution of income in the long run. 
Figure 9: Income Composition Inequality - Robustness

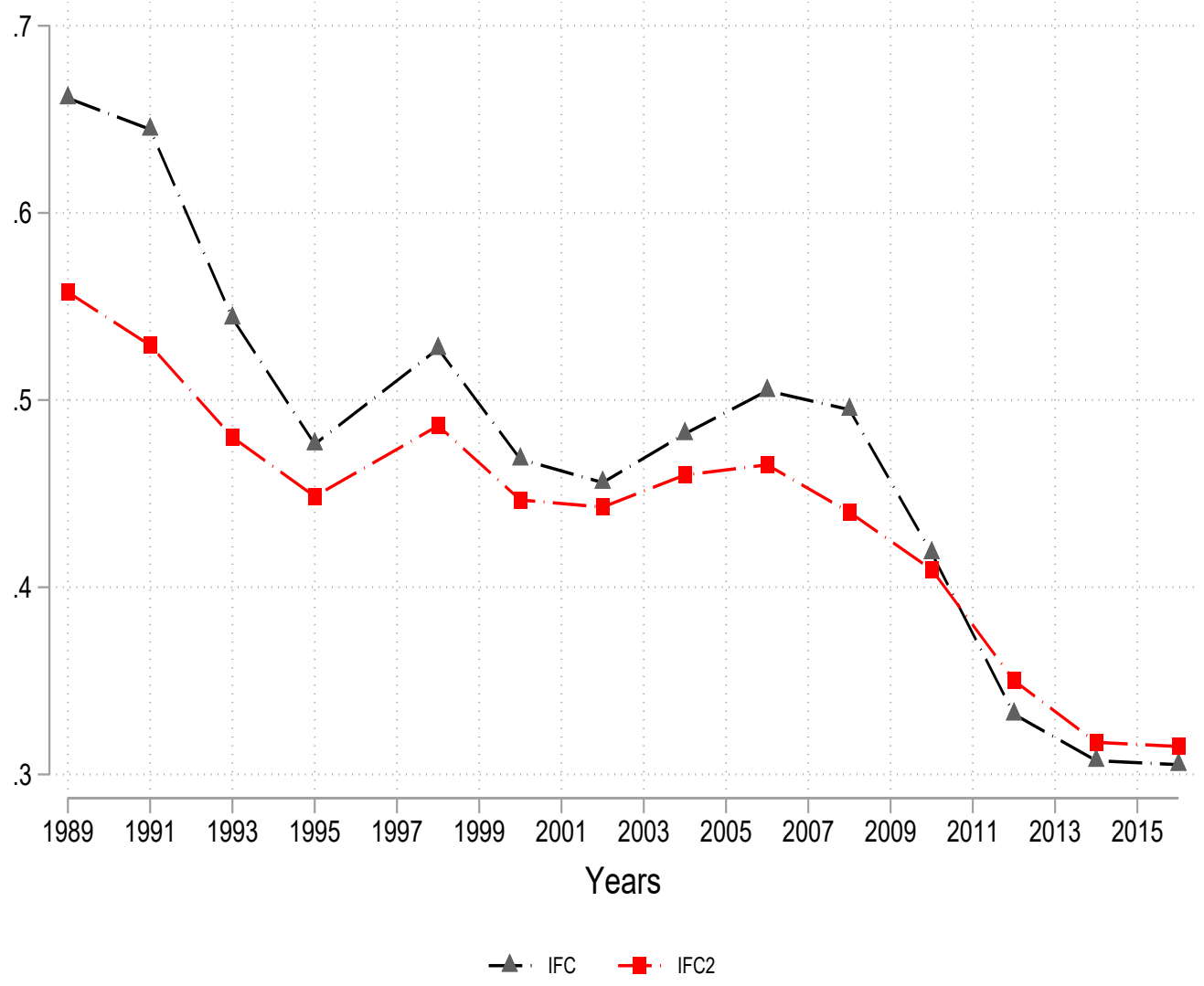

Note: The series $I F C$ considers capital income to be the sum of the capital component of self-employment income $\left(Y_{s \pi}\right)$ and property income $\left(Y_{p r}\right)$, and it considers labor income to be the sum of payroll income $\left(Y_{p a}\right)$ and the labor component of self-employment income $\left(Y_{s w}\right)$. Pensioners are excluded from the analysis. In contrast, the series $I F C_{2}$ includes pensions and transfers in the definition of labor income, leaving the definition of capital income unchanged. 
Figure 10: Income Composition Inequality - Robustness II

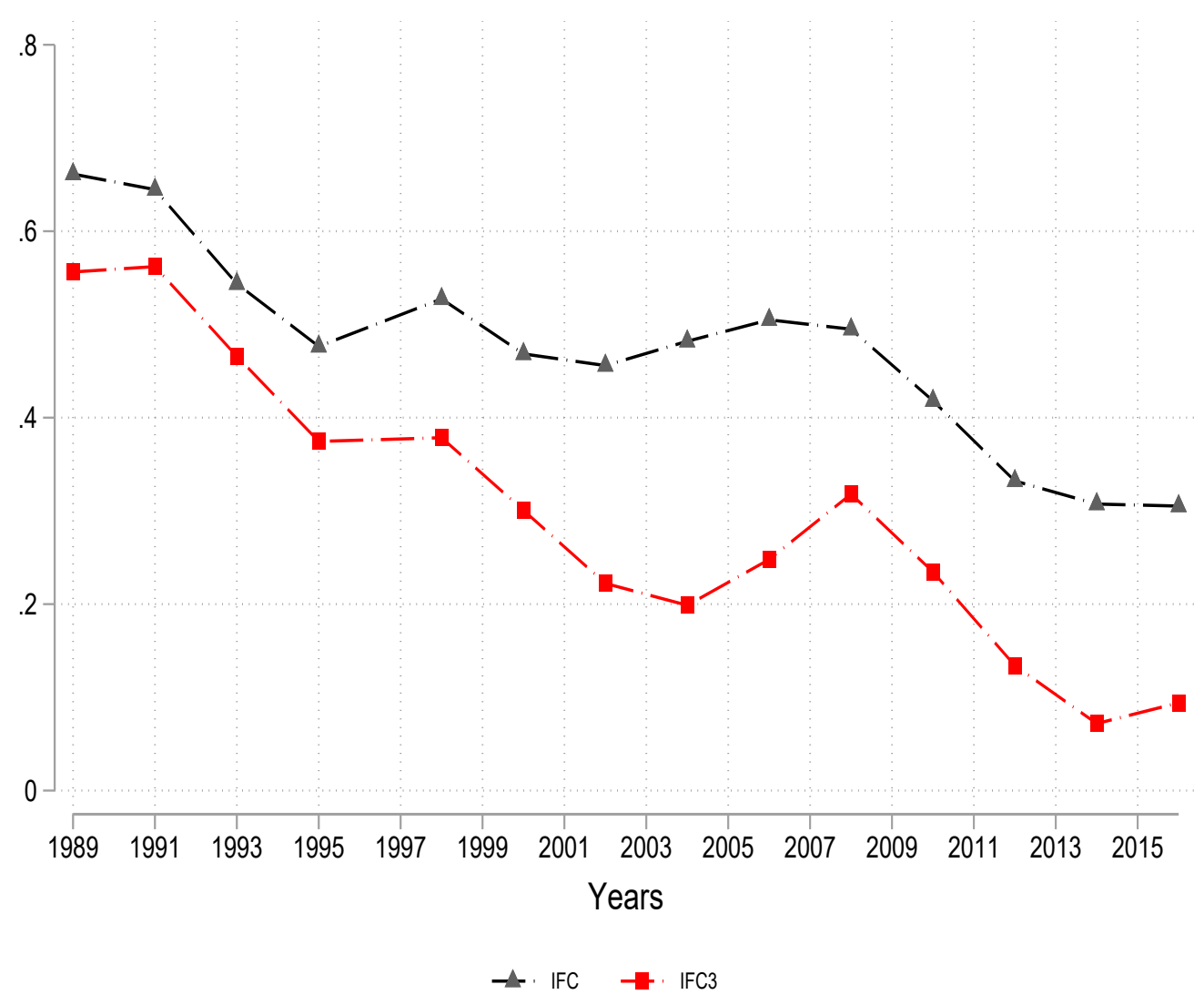

Note: The series IFC considers capital income to be the sum of the capital component of self-employment income $\left(Y_{s \pi}\right)$ and property income $\left(Y_{p r}\right)$, and it considers labor income to be the sum of payroll income $\left(Y_{p a}\right)$ and the labor component of self-employment income $\left(Y_{s w}\right)$. In contrast, the series $I F C_{3}$ defines labor income as the sum of payroll income and self-employment income, and capital income as property income. In both series pensioners are excluded from the analysis. 